\title{
RELATIONSHIP BETWEEN THE MECHANICAL EFFECTIVENESS OF PEDALLING AND THE CYCLE ERGOMETER SADDLE HEIGHT
}

\author{
Lachezar Stefanov, Ivan K. Ivanov, Daniela Aleksieva \\ National Sports Academy „Vassil Levski“, Sofia, Bulgaria
}

\begin{abstract}
Cycling is a sport that integrates man's physical condition and the technical parameters of the cycle. The position of the body in relation to the cycle is particularly important for obtaining results of this physical activity. Together with the other factors determining the right upright posture saddle height is also important. We studied the relationship between the Monark 618-E cycle ergometer saddle height and mechanical effectiveness when pedalling. For this purpose, we chose the Wingate cycle ergometer anaerobic test. We studied 8 men volunteers, aged between 19 to 25 years, all of them students at the National Sports Academy "Vasil Levski" in Sofia, with major - cycling coach. The research demonstrates that the lower height of the saddle compared to the one recommended in the "Heel" method, leads to lower mechanical effectiveness of pedalling in terms of W/kg body weight. This affects both the maximal and the average power of pedalling, with statistical significance of $99 \%$ determined by Mann-Whitney non-parametric test. Relative to the literature discussed, the study presents new evidence of the height of the cycle saddle for mechanical pedaling effectiveness.
\end{abstract}

Key words: Wingate; Anaerobic Test; Saddle Height; Mechanical Effectiveness; Maximal Power

\section{INTRODUCTION}

Cycling is a sport that integrates man's physical condition and the technical parameters of the cycle. The position of the body in relation to the bicycle is particularly important for obtaining results of this physical activity. Together with the other factors determining the right upright posture, saddle height is also important. The interaction between the cyclist's muscular power and the technical parameters of the cycle, determines the mechanical effectiveness of the work done. Scholars and coaches still disagree about the importance of the bicycle saddle height for the effectiveness of pedalling. Incorrect bicycle configuration may predispose athletes to injury and reduce their cycling performance (Bini, Hume, \& Croft, 2011).

The methods for determining the optimal saddle height have been well described in scientific literature (Bini, Hume, \& Croft, 2011; Peveler, Bishop, Smith, Richardson, \& Whitehorn, 2005). They are based on the relationship between the saddle height and the length of the lower limbs or the degree of flexion of the knee joint.

One group of authors use oxygen consumption as an indicator of the mechanical effectiveness. According to Ferrer-Roca, Bescós, Roig, Galilea, Valero, \& García-López (2014) the total effectiveness is significantly lower, and the oxygen consumption significantly higher when the saddle height increases. Similar results were reported by Nordeen (1977). According to his research, the $100 \% \mathrm{SH}$ (saddle heights) was most efficient, because mean values for 95,100 and $105 \%$ SH of oxygen consumption were 1.69, 1.61 and $1.74 \mathrm{lit} / \mathrm{min}$, respectively. Other investigators (Mandroukas, Angelopoulou, Christoulas, \&Vrabas, 2000) find that cycling with bent knee requires lower oxygen uptake while pedalling with straight knee is the only way to reach $\mathrm{VO}_{2 \max }$ during cycle testing, since the cardio respiratory system is fully taxed.

Another group of researchers use heart rate (HR) as an indicator of the mechanical effectiveness of pedalling. According to Titlow 
(1986), the knee angle has no effect on heart rate under a submaximal cycle ergometer load and the cyclists should be allowed to use a knee angle and a saddle height, which they find more comfortable. On the other hand, we found, that the heart rate is higher when the saddle is lower compared to the normal height at the same power for both loads (Stefanov, \& Kolev, 2015).

An interesting investigation evaluated the effect of the saddle height (determined as 96, 100 and 104 percentage trochanteric height) on heart rate, $\mathrm{VO}_{2}$, and lower limb kinematics. They tested 14 competitive male road racing cyclists during discontinuous submaximal exercise $(200 \mathrm{~W})$ on an air-resistance ergometer at seat tube angles of 68,74 and 80 degrees. At saddle height of $104 \%$ of trochanteric height, $\mathrm{VO}_{2}$ and heart rate were significantly higher and power efficiency significantly lower than both $96 \%$ and $100 \%$ trochanteric height (Price, \& Donne, 1997).

The results of another study (FerrerRoca, Bescós,Roig,Galilea, Valero,\&GarcíaLópez, 2014) indicated that small changes in saddle height affected gross efficiency and lower limb kinematics.

The aim that we set was to investigate the dependence between the cycle ergometer saddle height and the mechanical effectiveness of pedalling. In order to determine the mechanical effectiveness of pedalling we chose the Wingate cycle ergometer anaerobic test (WANT). This test is accepted as the „Gold Standard" for determining the maximal anaerobic power on cycle ergometer tests.

\section{MATERIALS AND METHODS}

We studied 8 men, volunteers aged between 19 and 25, all of them students at the National Sports Academy "Vassil Levski" in Sofia, with major - cycling coach. They were previously made familiar with the object and nature of the experiments and gave their informed assent to take part in the investigation.
We determined the maximal relative anaerobic power $\left(\mathrm{P}_{\max / \mathrm{rel}}\right)$ and the average relative anaerobic power $\left(\mathrm{P}_{\text {aver/rel }}\right)$ of every one of the participants under two conditions, each of which was studied in a separate experiment by means of WANT. During the investigation we used a Monark 618-E cycle ergometer. In the first experiment the saddle height was adjusted by the "Heel" method and we designated it as height 100\% (H100). With the Monark 618-E cycle ergometer the saddle height is fixed with a bolt in a row of holes along a supporting square profile. In the second experiment, the test was conducted with the saddle height three holes lower than the one in the first experiment. We designated this height as HL. During both experiments both conditions were identical with the exception of the saddle height. The frequency of pedalling was determined through a system of tensiometric pedals (Stefanov, 2016), which allowed for a more accurate determination of the number of revolutions per 5 seconds realized by the athlete.

We conducted the WANT in the following way:

We determined the force of loading $(F)$ in $\mathrm{N}$ according to the following formula for athletes - $\mathrm{F}=$ body weight $(\mathrm{kg})$ x9.8

(2) We performed a warming upon a cycle ergometer for 5 minutes. In the last 5 seconds of every minute a sprint took place, which intensity was equal to the work load.

(3) We turned the pedals slightly with minimal resistance for 3 minutes.

(4) There was 2 min. rest on the cycle ergometer. During this time the software was turned on and EXCEL was launched. Then the respective USB port for transferring the data was activated.

(5) A period of acceleration for $15 \mathrm{~s}$ followed, which included 10 seconds of pedalling with $1 / 3$ of the work load (which is $F$ $x$ 0.33) with 30 revolutions / min. The work level was reached in the remaining 5 seconds.

(6) The test went on for 30 seconds at top 
speed. The test started with a recording from the software. The recording was stopped at the $30^{\text {th }}$ second.

(7) This was followed by a 3-minute cool down at $50 \mathrm{~W}$ power and unspecified revolutions.

The frequency of pedalling was determined by a system of tensometric pedals ${ }^{9}$, which allowed a more precise determination of the number of revolutions for 5 seconds. The strain pressure on the tensometric pedals was recorded every $100 \mathrm{~ms}$. After determining the number of revolutions for all 5-second intervals, we determined $\mathrm{P}_{\text {max }}$ and $\mathrm{P}_{\text {aver }}$ for each of the participants under both experiment conditions, H100 and HL.

The formulas we used are the standard ones for this test.

\section{Power}

$$
\mathrm{P}=\text { F.n.6 in Watt }
$$

where $\mathrm{F}$ is the force (in Newton); $\mathrm{n}-$ the number of revolutions per 5 seconds

\section{Maximal Power}

$$
\mathrm{P}_{\text {max }}
$$

It is determined by the 5-second interval when the power is at its greatest.

\section{Total Power}

$$
\mathrm{P}_{\text {tot }}=\text { F.n. } 6
$$

$\mathrm{n}$ - the number of revolutions per $30 \mathrm{sec}-$ onds

Average Power

$$
\mathrm{P}_{\text {aver }}=\mathrm{P}_{\text {tot }} / 30
$$

The indicators we compare between the different participants are:

\section{Relative maximal power}

$$
\mathrm{P}_{\max / \mathrm{rel}}=\mathrm{P}_{\text {max }} / \mathrm{kg}
$$

(maximal power divided by the body weight of the person in $\mathrm{kg}$ ).

\section{The relative average power-}

$$
\mathrm{P}_{\text {aver/ rel }}=\mathrm{P}_{\text {aver }} / \mathrm{kg}
$$

(average power divided by the body weight of the person in $\mathrm{kg}$ ).

Data was recorded and processed with MICROSOFT - EXCEL and „PLX-DAQ recorder" open source interface software, available freely on the Internet. The results were analyzed with the MaxStatLite - 2015 statistical software, freely available on the Internet.

\section{RESULTS}

From the raw data under both experimental conditions: H100 and HL we calculated the relative maximum power and the relative average power for each of the subjects, which are presented in Table 1.

Table 1. Shows the maximal relative power as well as the average power $P_{\max r \text { rel }}$ and Paver I rel for every one of athletes studied under both conditions (H100 and HL) of the experiment.

\begin{tabular}{cllll}
\hline & $\mathbf{P}_{\text {max/rel }} / \mathbf{H 1 0 0}$ & $\mathbf{P}_{\text {max/rel }} / \mathbf{H L}$ & $\mathbf{P}_{\text {aver/rel }} / \mathbf{H 1 0 0}$ & $\mathbf{P}_{\text {aver/rel }} / \mathbf{H L}$ \\
\hline S.V. & 14.63 & 9.00 & 11.06 & 7.31 \\
\hline B.P. & 13.00 & 9.75 & 11.56 & 7.58 \\
\hline K.M. & 10.91 & 7.64 & 8.18 & 6.36 \\
\hline M.V. & 10.43 & 9.39 & 8.47 & 7.59 \\
\hline A.K. & 9.53 & 8.47 & 8.70 & 8.00 \\
\hline M.S. & 9.49 & 8.43 & 7.38 & 5.97 \\
\hline S.S. & 9.47 & 8.42 & 8.60 & 6.49 \\
\hline T.P. & 8.96 & 6.72 & 7.47 & 5.97 \\
\hline
\end{tabular}


The surveyed persons and their indicators, presented in table 1 are arranged from the larger to the lower value of $\mathrm{P}_{\max / \text { rel }}$ for the $\mathrm{H} 100$ condition. In the first column of tablel the initials of the surveyed persons are presented. In the second column $\mathrm{P}_{\max / \text { rel }}$ is presented for the H100 condition, where the highest value is $14.63 \mathrm{~W} / \mathrm{kg}$ and the lowest is $8.96 \mathrm{~W} / \mathrm{kg}$. In the third column the values of $\mathrm{P}_{\max / \text { rel }}$ for the HL condition are presented, where the highest value is $9.75 \mathrm{~W} / \mathrm{kg}$ and the lowest $6.72 \mathrm{~W} /$ $\mathrm{kg}$. In columns 4 and 5 the values for the relative average power are provided, respectively H100 and HL.

\section{DISCUSSION}

The relative maximum power and relative mean power show the mechanical efficiency of pedalling for each of the participants in the experiment. The relatively large difference in the power realized between the participants is noticeable, but the trend towards lower efficiency under the HL condition compared to H100 is obvious. Table 1 shows that the difference between $\mathrm{P}_{\max / \text { rel }}(\mathrm{H} 100)$ and $\mathrm{P}_{\max / \text { rel }}(\mathrm{HL})$ is greater than the difference between $\mathrm{P}_{\text {aver/rel }}$ (H100) and $\mathrm{P}_{\text {aver/rel }}(\mathrm{HL})$, which is probably due to the greater difference in the relative maximal powers under $\mathrm{H} 100$ between the participants.

Figure 1 shows $\mathrm{P}_{\max / \text { rel }}$ for $\mathrm{H} 100$ and HL conditions. The ordinate reflects the relative power $\mathrm{P}_{\text {max/rel }}$ for each person under study. In all tested individuals the mechanical efficiency under HL conditions was lower.

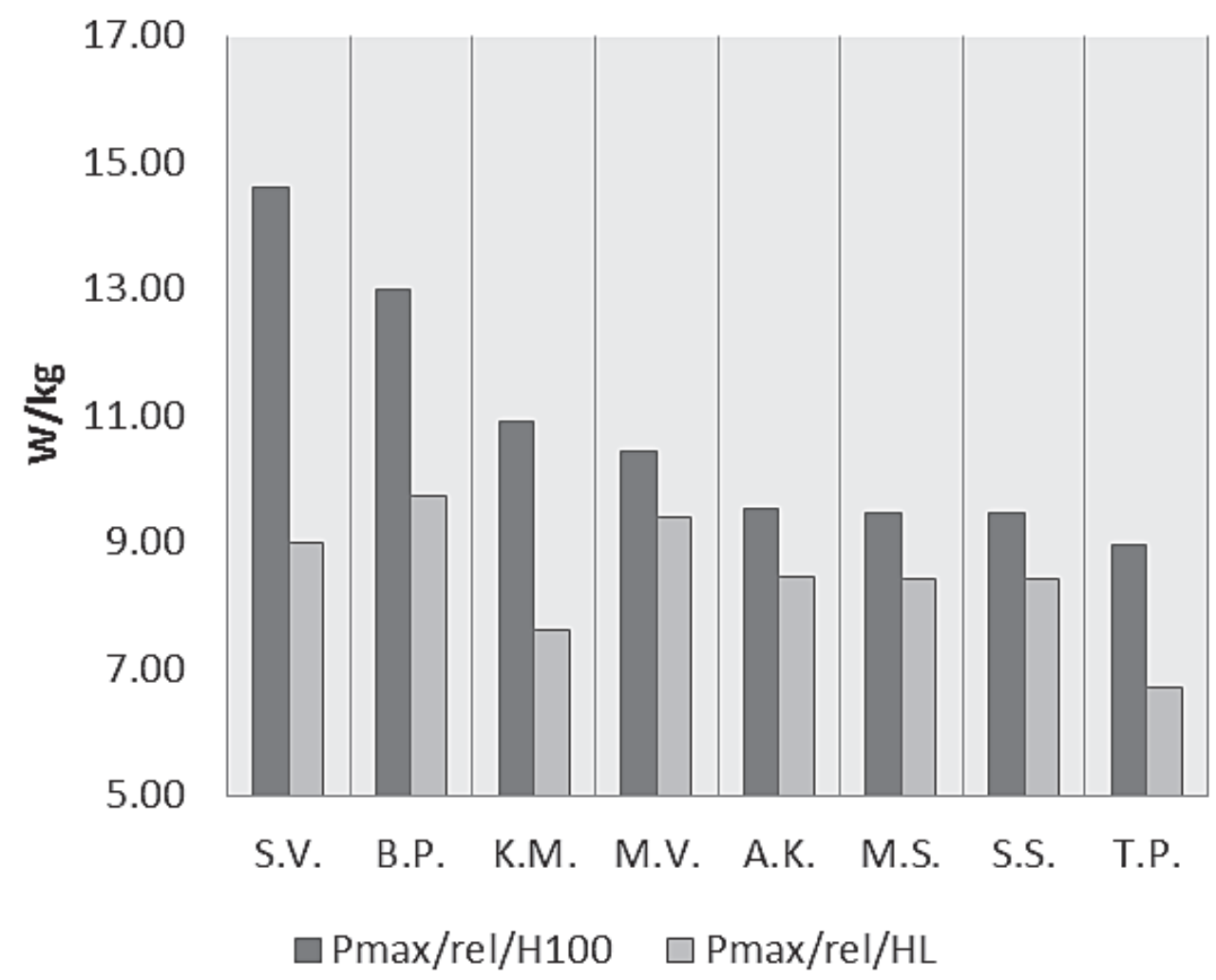

Figure 1. Shows the relative maximal power in conditions $H 100$ and $H L$ in $W / k g$ along the $y$ axis for every athlete studied, which are entered along the $x$ axis. 


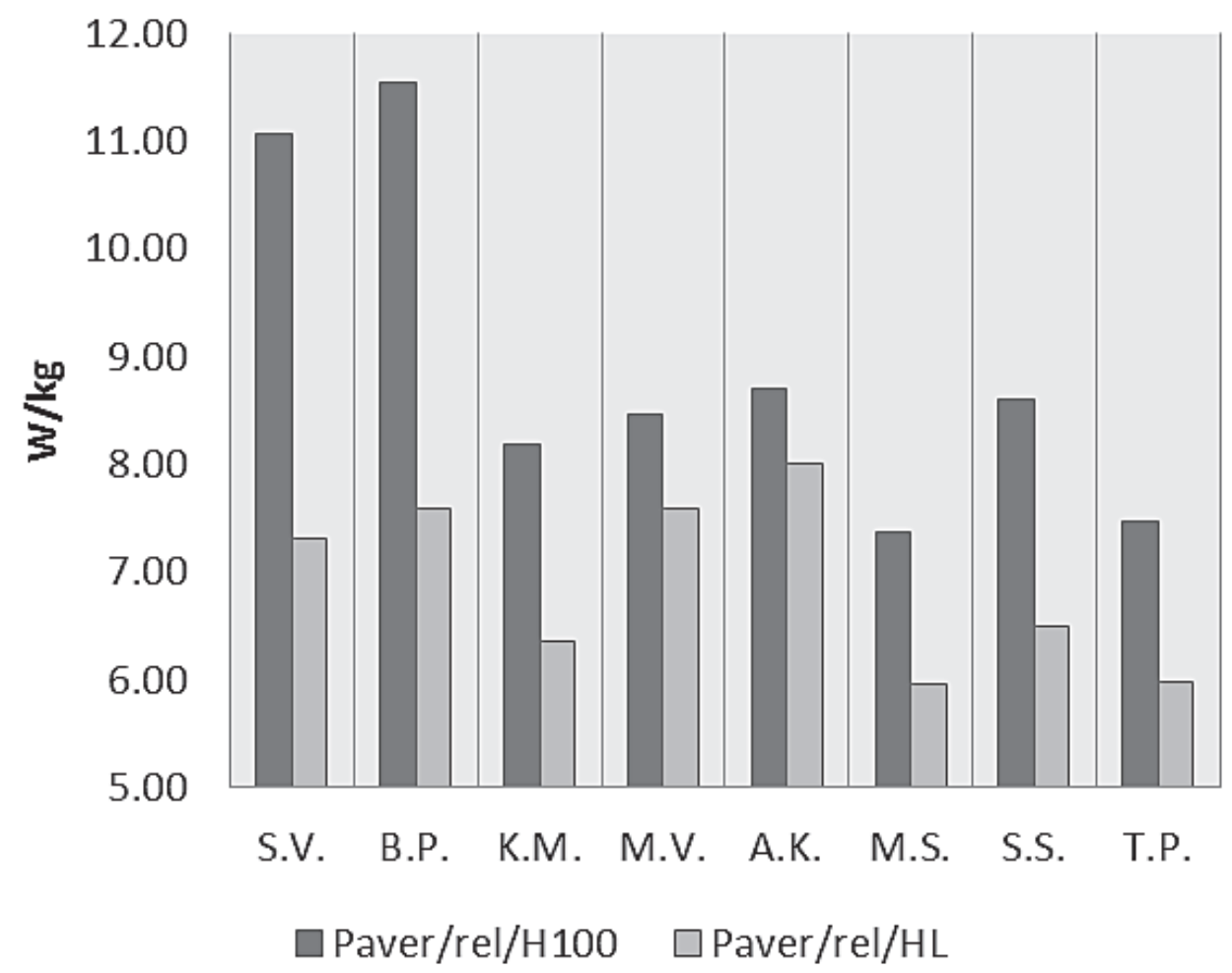

Figure 2. Shows the average relative power in conditions $H 100$ and $H \mathrm{~L}$ in $\mathrm{W} / \mathrm{kg}$ along the $y$ axis for every one of the participants, who have been entered along the $x$ axis

At the average relative power, $\mathrm{P}_{\text {aver/rel }}$, higher values were also observed for all participants under the H100 conditions compared to HL (Fig. 2). Among some of the participants, the differences in pedalling efficiency under both conditions of the experiment are very large, and among others it is comparatively smaller. This can be caused by many factors, but more important ones are the genetically predetermined ratio between type-I and typeII muscle fibres, current health status and the physical training of the participant. The contingent is such that we can exclude gender and age factors.
To prove the statistical significance of theobserved differences, we used Mann Whitney's nonparametric test. This was imposed by the fact we surveyed few participants and could not correctly determine the statistical distribution of the investigated indicators. The test showed a 99\% statistically significant difference between the relative maximal powers measured under H100 conditions versus the HL conditions of all participants in the sample. The relative mean powers measured for all conditions H100 and HL also differed with a statistical significance of 99\% (Table 2).

Table 2. Shows the results of the comparison between Pmax / rel and Paver / rel by Mann-Whitney test

\begin{tabular}{ccc}
\hline Mann-Whitney & $\mathrm{P}_{\max / \mathrm{rel}}$ & $\mathrm{P}_{\text {aver/rel }}$ \\
\hline $\mathrm{p}$ & 0.0063 & 0.0063 \\
\hline
\end{tabular}

The probable difference between the two samples is $99 \%$ at $\mathrm{p}<0.01$ 


\section{CONCLUSIONS}

This study proves that the lower height of the cycle saddle, compared to the "Heel” method recommended, results in a lower mechanical efficiency of pedalling expressed in $\mathrm{W} / \mathrm{kg}$ body weight. This reflects both the maximal and the average pedalling power. For this reason, we recommend that the height of the saddle be correctly determined by the "Heel” method, especially during cyclists' initial training period.

\section{REFERENCES}

Bini, R., Hume, P.A., \&Croft, J.L.(2011). Effects of bicycle saddle height on knee injury risk and cycling performance. Sports Med., 1;41(6), : 463-76

Ferrer-Roca., Bescós, R., Roig, A., Galilea, P., Valero, O., García-López, J. (2014). Acute effects of small changes in bicycle saddle height on gross efficiency and lower limb kinematics. Journal of Strength and Conditioning Research.,28(3), 784-91

Mandroukas, K., Angelopoulou, N., Christoulas, K., \&Vrabas, I.S. (2000). Cardiorespiratory and metabolic responses during straight and bent knee cycling. The Journal of Sports Medicine and Physical Fitness, 40(2), 145149

Nordeen-Snyder, K.S. (1977). The effect of bicycle seat height variation upon oxygen consumption and lower limb kinematics. Med- icine And Science In Sports, 9(2), 113-117

Peveler, W., Bishop, P., Smith, J., Richardson, M.,\&Whitehorn, E. (2005). Comparing Methods for Setting Saddle height in Trained Cyclists. Journal of Exercise Physiology Online, Vol. 8, No. 1, pp. 51-55

Peveler, W. W. (2008). Effects of saddle height on economy in cycling. Journal of Strength and Conditioning Research / National Strength \& Conditioning Association, 22(4), 1355-1359

Price, D., \& Donne, B. (1997).Effect of variation in seat tube angle at different seat heights on submaximal cycling performance in man. Journal of Sports Sciences, 15(4), 395-402

Stefanov, L., \&Kolev, I., (2015). Cyclists Saddle Height Importance on the Results of Bicycle Ergometer Test "Astrand\& Rhyming".International Journal of Scientific and Professional Issues in Physical Education and Sport, Vol.5, No.1, 47

Stefanov, L.G., (2016). Wireless cycle power-meter system with load cell. International Journal of Scientific \& Engineering Research, Vol.7, Issue 7, 805-809

Titlow, L., Ishee, J., \& Anders, A. (1986). Effects of knee angle on submaximal bicycle ergometry. Journal of Sports Medicine \& Physical Fitness, 26(1), 52-54

\section{Correspondence:}

Lachezar Stefanov

National Sports Academy "Vassil Levski"

Department of Physiology and Biochemistry Studentski grad, 21, Acad. Stefan Mladenov Str.

Sofia 1700, Bulgaria E-mail: luchos@abv.bg 